\title{
Brief Probe into the Brand and Marketing Strategy of NBA
}

\author{
Zhongfeng Sun ${ }^{1}$ \\ ${ }^{1}$ Department of Physical Education, Qingdao University of Science \& Technology, Laoshan District, Qingdao, \\ Shandong, China \\ Correspondence: Zhongfeng Sun, Department of Physical Education, Qingdao University of Science \& \\ Technology, Laoshan District, Qingdao 266061, Shandong, China. E-mail: sunzhongfeng1976@163.com
}

Received: May 20, 2015 Accepted: June 11, 2015 Online Published: June 13, 2015

doi:10.5539/ass.v11n16p183

URL: http://dx.doi.org/10.5539/ass.v11n16p183

\begin{abstract}
Sports marketing one of many marketing ways which integrates the sports culture and brand culture through sports activities. Sports marketing have two explanations, one regards sports as a commodity, and the other is to regard the sports activities as the carrier of brand marketing. In this paper, we use the second kind of explanation that sports marketing is regarded as a carrier of brand marketing.

Nowadays, with the constant development of all kinds of sports, many sports have reached a certain height through their own development strategy and marketing strategy, and form various league and sports leagues, but there isn't one international sports media group like the National Basketball Association (NBA) that is popular all over the world. Marketed through the stars and the surrounding products, the unique marketing strategy is gradually referred to by other league and activities. This article will firstly introduce the current situation of the NBA, expound the importance of sports marketing to brand promotion and sports promotion, then analyze sports marketing strategy, and finally put forward the conclusion of this article and give a summary to this article.
\end{abstract}

Keywords: NBA, sports marketing, brand, business

\section{Introduction}

People's passion for sports is in the process of improving in modern society, the popularity of a sport is in direct proportion to the breadth of their audience. Sports marketing are a marketing campaign to promote their products and brands taking sports activities as the carrier. The right marketing strategy is the key to gain promotion and development of the brand, the product strategy taking consumer demand as the center, the global promotion strategy and the brand strategy taking NBA culture as the core makes NBA become the first big professional basketball tournament in the United States, and be the richest league in the four major professional leagues.

\section{The NBA's Marketing Strategy}

\subsection{The Global Promotion Strategy}

\subsubsection{Introduce International Basketball Stars}

In the past years, NBA introduced many international basketball stars, such as Yao Ming, Wang Zhizhi, Yi Jianlian, Yao Ming had the largest effect on NBA among the stars. After Yao Ming entered NBA, more and more people have been paying attention to professional basketball, he has brought huge audience to NBA. He is really a giant, throughout his career, China central television (CCTV) collected statistics of 39 Rockets' games in the regular season, there are about two hundred million viewers who watched the Rockets games through TV or Internet, it occupies a third of the audience in the NBA. While the number of people watching the NBA playoffs from China is more than 1.95 billion, it is probably twice as many as the super bowl attracted. The Rockets' commercial value had been $\$ 439$ million from $\$ 85$ million in 1993, after Yao Ming came into Rockets.

\subsubsection{Broadcast around the World}

Before 1998, NBA is free to send content and the signal, only adding some advertisements live on TV. In the all-star game and the playoffs CCTV is invited to broadcast the games, although there is no return temporarily, a deep fan base of NBA has been laid in China, the most populous country. According to a new report from the NBA's official website, the 2005-06 season NBA games spread to 215 different countries and regions by 43 languages and 164 different televisions, involving the audience of 3.1 billion people. At the same time of 
broadcasting around the world, the NBA paly games in China and Japan to increase interacts with the fans, it earns the NBA fame and fortune.

\subsection{All-Round Marketing Partners}

\subsubsection{High Quality Television Relay}

In the beginning, NBA is just an amateur league; there are no commercial elements involved. NBA received $\$ 39000$ for the first time as the retransmission fee of 13 games until to 53-54 seasons. After the development of 60 years, NBA has become a very mature sports activity with high level of profession, and the development of television relay cannot be mentioned in the same breath. NBA copyrights include wireless TV broadcast rights, satellite television broadcast rights, cable television broadcast rights, etc. The authorization of the television copyright is divided into regional copyright, national copyright, intercontinental copyright and copyright around the world. The professional division and television relay operation level ensures the high quality level of broadcasting. The commercial sports reported in 2014, NBA has negotiated a new contract on television relay, the contract income of broadcast a year is expected to more than $\$ 2$ billion; the contract will be effective from 16-17 seasons. The NBA's new President Adam Silver has shown his talent and ambition in business, even though the NBA existing TV relay contract will expire until 2016, Adam Silver has negotiated a new sky-high price broadcast contract ahead of schedule. According to the new contract, the broadcasting costs of one year will be more than $\$ 2$ billion. Among them, the ESPN will pay more than $\$ 1$ billion every year.

\subsubsection{Strong Marketing Partners}

The NBA has numerous strong marketing partners. The NBA partners in China market have up to six in 2005, thus it can be seen that NBA is a good place for publicity. According to a survey in March $2003,75 \%$ of the men aged 15 to 24 were the fans of NBA. For the all participants aged 15 to 24 years old and 15 to 64 year old in the survey, $58 \%$ and $43 \%$ respectively were the fans of NBA. Broad audience let NBA become the darling of the advertising, the NBA's sports shoes and sportswear business partners include Adidas, Reebok, Nike, drink business partners include Coca Cola, and McDonald's is NBA' food business partner. In 2005-06 season, NBA already has 17 business partners around the world. NBA gets great economic benefits sponsored by advertising and intangible publicity. On the other hand, NBA also provides a good medium for sponsors to advertise themselves.

\subsection{The Basketball Peripheral Products}

In the 20 years when Stern was President, he made a modification of almost all the NBA's rules and regulations, marketing and management means, operation concept and internationalization via a unique marketing strategy, and he also established all sorts of entertainment about NBA. With more and more commercialized of sports, the pattern of NBA has almost become the template of all kinds of operation mode, and also provides a good opportunity for other sports to learn. In the 20 years, the NBA's total assets expanded 5 times.

The basketball game is the NBA's main product, but each year more than 1000 regular season games and dozens of playoff games are just one part of the NBA's products. The all-star game, NBA draft, overseas competition, basketball carnival, basketball without borders, the NBA training camp, and basketball caravan are the direct extension products of NBA. In addition, NBA also invites basketball stars to shoot film and television products, including the game video tapes, videos, music and other multimedia products.

\section{The NBA's Brand Strategy}

The essence of an enterprise's profits is a game with customers, and how to use its existing resources to create its own value according to the needs of consumers. This requires the enterprises clear their own core values and give full play to the core values of education effect in practice on the basis of understanding consumers' heart carefully, the motive why they buy the products, the characteristics between industries and the competition brand advantage. Brand is a kind of intangible wealth of an enterprise, with this wealth; enterprise can use this intangible wealth to create an immeasurable value. The essence of enterprise competition is product and brand, the NBA's product is professional league. As we all know, the NBA career games represent the highest level. The competitiveness of the NBA brand is equal to the high level league.

An enterprise could not succeed without the support of strong brand, the development and growth of brand is the success road of an enterprise. The development of brand is also the development of enterprise culture, enterprise culture is the foundation and soul of the enterprise, outstanding and unique enterprise culture can bring intangible business value for the enterprise. As is known to all, the brand Microsoft has created an inestimable social value; its brand has not only created the much value for Microsoft Company, but also had a profound impact on the world and changed people's way and level of life. The value of the brand is so big, how to develop 
a brand and how to maintain the brand is the real problem faced by an enterprise. In the process of developing its brand, the enterprise should also pay attention to its social value. The social value of NBA embodies that it promoted the basketball to a whole new level, and defined the development direction of basketball. How to make a win-win situation of the brand and social value is a problem which the enterprise managers should think seriously about, it should be done by a successful enterprise to develop and expand the brand in the long run. A correct brand strategy can drive the development of a enterprise, make the enterprise play a more important social value. The NBA's brand strategy takes the NBA to a new road.

\subsection{Brand Alliance and Muti-brands Strategy}

Brand alliance strategy involves two or more than two franchisors, they unite the brands in order to create better products or services, and use two or more brands on the same product or service to realize the complementary advantages and the strengths of each brand. This is the co-branding strategy. NBA teams are independent individuals, and their bosses operate independently. The 30 teams have 30 brands; these 30 brands are not only the brand of NBA, but also the NBA's joint brands. These teams manage for their own brands, hold brand promotion event, recruit star players to enhance the team, and develop team related products to attract fans, so as to realize profits. The team's brand belongs to the NBA, and the NBA league also protects these teams.

\subsection{Brand Franchising Strategy}

The franchisor and franchisee realize the brand expansion in the same mode with the aid of the same brand in order to achieve the win-win or multi-win purpose. The franchisee can use the technology and brand only paying a certain fee to the franchisor. Brand franchising strategy has many advantages; it can not only get many funds at a lower risk, but also expand the brand rapidly. Many multinational companies use the brand franchise, and McDonald's success is derived from the brand franchise. The NBA uses brand franchise in the development of peripheral products, the franchise of brand and technology reduces the additional advertising spending of NBA, not only advertise for the NBA, but also provide a broader platform for NBA. NBA integrated its own mode of development into the successful experiences; make the brand franchise a new understanding.

\subsection{The Virtual Management of Brand}

Brand virtual operation liberates the productive forces, makes the enterprise no longer focus on the complicated production and transaction, and puts more effort in the technology, service and brand promotion. Brand maintenance is a long-term process, no matter what a new brand, or consolidating and improving an existing brand, it must analyze the market positioning of brand, brand recognition guide, brand building and control constantly. NBA focuses on brand promotion in the virtual business, separates its center from production, and has more plentiful energy to develop brand to make the fame of NBA far and wide.

\section{The Effect of the NBA's Marketing Strategy on the Sports of Our Country}

Throughout the NBA's growth, from anonymity to sports giant, the addition of commercial elements makes it form a complete management system. The high income of athletes and coaches arouse and stimulate the competition between the industries greatly, NBA makes a perfect union of competitive sports and sports economy. The economic interests promote the development of the industry, and also promote the strong competition between enterprises. Chinese competitive sports also become professional and market-oriented in the tide of history, but our system and competition mechanism is in the transition period with a clear system of loopholes and questions because of our economic and political system. It is difficult to obtain the economic benefits brought by the development and utilization of sports resources before the problems are solved.

NBA has set an excellent example for the Chinese Basketball League, which brings in a development mode with market economy as the main body and market regulation as the main method. We watch the NBA and learn its operation model, which gives the League a good direction, avoids many twists or detours, and benefits to NBA basketball league to the development and operation of the League. With a century's development experiences, NBA is worthy of our learning and reference. Strengthening cooperation and exchanges with NBA is sure to benefit the development of Chinese basketball and the operation of the League a lot. Because of Yao Ming*s presence, the television coverage rates of CCTV NBA game has multiplied, numerous fans became crazy Yao Mi. They regard Rockets as the home team in China, they are rejoiced in the victories of Rockets and sad for its failures, because a Chinese named Yao Ming in the team. Chinese fans have a Rockets complex. If there is any chance of our clubs bringing in players like Yao Ming in the NBA, can our League perform as wonderful as Yao Ming did in Rockets and thus bring enormous business profit both in domestic and world? All the facts show that, NBA and Chinese basketball is accelerating integration, Chinese basketball has learned a lot of advanced 
concepts through NBA. The centuries-old wealth of NBA operation is worthy of our pursuing and provides us an opportunity to learn marketing.

\subsection{Overseas Market Development}

NBA always pays attention to the overseas market development. Based on the development of domestic market, NBA actively explores to broaden the international market, goes to the world based on the United States. NBA can be seen everywhere in our life, it is translated between people more like a kind of culture, the sports culture not only spread widely in the society, but also affect the teenagers group after group. There are a lot of overseas professional athletes to participate into NBA every year, this successfully promote NBA free of charge. NBA is also a melting pot mixing together various cultures. It learns the local culture, and integrates the local culture into NBA in the process of overseas development market, takes its essence to form its own unique competitiveness.

\subsection{The Complete Human Resources Management Solution}

Talents are the primary resources in any period. The players' ability is the first resource in competitive sports; it is the sole criterion for evaluating the players. The sports of our country is not a lack of good players, the shortage is sports management talent from the current situation of sports industry in our country. The management of sports industry has no purpose, develops blind all kinds of sports, does not focus on a campaign, and also does not have a set of its own development model, struggling in the development. We should grasp and use of market rules, perfect the deficiency of the sports industry, and faces the problems in the sports developing of our country. It does not copy completely to draw lessons from successful experience of history, but also solve practical problems according to the situation of our country. Cultivating a group of talents with professional sports knowledge and a certain management ability and operation ability is the key to further develop our country's sports market.

\subsection{The Long-Term Development Direction}

Take basketball as example, we should determine the market direction after knowing the market demand, drawing the successful lessons from NBA. In other words, we should make rational decisions after comprehensive understanding of the market, remember that never make decision autonomous blindly, and set up a long-term development direction. Change the past game mode, improve the competition of athletics and enhance the art of the game to attract more viewers and raise public awareness of the brand. Modern people pay more and more attention to sports, and regard sports as a leisure entertainment in life. Developing the sports economics is not only the needs of meeting the global market economy, but also an important measure to promote our country sports reform and strengthen the development of the sports. We should give full play to the advantages of sports in our country, focus on the development of competitive sports, promote the weak sports with the strong ones, and realize the common development. We should also follow the pace of the government in macro policy, gradually establish its own brand in the medium industry, and gradually enhance competitiveness on the microscopic sports carefully draw on successful experience in the NBA under the gradually perfect sports market system. Only in this way, can we put my sports of our country economy to the positive and normative development track and let our country to power sports country from big sports country.

\section{References}

Che, T., \& Zhang, Y. P. (2009). The Research of CBA League Market Development Strategy in China. Journal of Chifeng University, 25(9).

Gao, C. X. (2007). NBA successful operating mode's inspiration to China sports economy development. Special Zone Economy, 219(4).

Wei, L. (2010). Revelation of NBA Development. Sports Science Research, 31(3).

Wu, J. (2010). Analysis of Problems in Sports Marketing and Implementation Strategy. China Business \& Trade.

Yang, Z. L. (2003). An Analysis of Domestic Brand Expansion Strategy. Fujian Tribune (A Economics \& Sociology Monthly), (12).

Yang, Z. S., \& Wang, X. B. (2006). A Brief Analysis of NBA's Marketing Strategies. Social Sciences Review, (8).

\section{Copyrights}

Copyright for this article is retained by the author(s), with first publication rights granted to the journal.

This is an open-access article distributed under the terms and conditions of the Creative Commons Attribution license (http://creativecommons.org/licenses/by/3.0/). 